\title{
HERBERT MELVIN LIEBERSTEIN
}

\author{
R. G. KEATS
}

Professor Herbert Melvin Lieberstein died at Royal Newcastle Hospital on 18th August, 1973, at the age of 47. As an applied mathematician, Professor Lieberstein was devoted to his research and teaching in the application of mathematics to other disciplines; his most recent book entitled "Mathematical Physiology", was published just before his death. Because his interests coincided so closely with the aims and aspirations of the Faculty of Mathematics at Newcastle, his appointment to that Faculty in 1971 was particularly appropriate. He lived less than two years in Australia, but during that time he consolidated his reputation as a most versatile and successful applied mathematician. His work is well known throughout Australia and, indeed, throughout the world, especially to those who work in fields to which mathematics may be profitably applied. However, his versatility and ability were not confined to mathematics, for he also made substantial contributions to a number of community projects; these contributions will be long remembered by those interested in the welfare of the Australian Aborigines, problems of the environment and associated projects.

He leaves a widow, Mary-Anne Lieberstein, who has now returned to Tucson, Arizona. I am very grateful to her for providing material for this article.

Since I had known Mel for less than two years, I relied heavily on his friends and colleagues in Northern America for information on his professional activities before coming to Australia. I gratefully acknowledge this help and, in particular, I would thank Dr. Charles Bryan of the University of Montana. I also thank Reverend W. Brown, Secretary of the Hunter Region Aboriginal Cooperative Limited, who helped considerably with information concerning Mel's work with the Australian Aborigines.

Herbert Melvin Lieberstein was born at Springfield, Missouri, United States of America, on 20th September, 1925. His parents, Ely and Clara Lieberstein, are now living at Los Angeles, and are extremely proud of the mathematical stature achieved by their son. They were not academics, nor were other members of the family; almost without exception they were business people. Mel's achievements as a mathematician were entirely due to his ability and tremendous drive, apart from some encouragement, especially from his wife. This personal drive, 
coupled with enormous enthusiasm, was also clearly evident in his non-mathematical activities.

After graduating from the University of Arkansas in 1947 with B. A. and B.S., Mel obtained an M.A. in mathematics from the University of Kansas and then spent some years as a mathematician at the Naval Proving Ground. In 1954 he returned to university work as a Research Associate at the Institute of Fluid Dynamics and Applied Mathematics, University of Maryland. While at Maryland he obtained his $\mathrm{Ph}$. D. for research on the "Existence and uniqueness for boundary value problems of the Euler-PoissonDarboux equations" under the supervision of Dr. A. Weinstein.

From 1956-1958 Dr. Lieberstein worked as a Numerical Analyst at the Ramo-Wooldridge Corporation, and then for two years as Associate Professor at the Mathematics Research Centre, University of Wisconsin. His publications during these five years exhibit his profound appreciation of the triumphs and shortcomings of numerical analysis at that time. Some of this work, for example that on continuous methods, was probably well ahead of its time.

In the 1960's Lieberstein spent periods of about three years at a number of universities in the United States of America, including Arizona, New Mexico Highlands, North Carolina State and Indiana. His last post in North America was Research Professor of Mathematics at Wichita State University. His pioneering work in mathematical physiology developed during this period; mathematically it was well founded on his mastery of the theory and practice of partial differential equations and numerical analysis. His first papers in this field appeared about 1964. This work was continued vigorously at Newcastle, and at his death he had proposed the establishment of a Research School in Mathematics in the Life Sciences and Medicine. This proposal had received considerable support in Newcastle.

Lieberstein's contributions to mathematics and its applications are essentially contained in his three books [1], [2], [3]. The first, entitled "A Course in Numerical Analysis", was published in 1968 and recommended for those senior and post-graduate students who, like his own students, feel

"that someone should try to make their training in applied mathematics more generally conform to modern training in mathematics."

His approach to the subject is best illustrated with his own words.

"We regret the almost universal tendency for books on numerical analysis to treat the subject exclusively within its own mathematical framework without showing the excitement of the applications that bred the subject. For us a great richness in the subject arises from its uses in elucidating phenomena of nature or analyzing technological problems. Here lie our true motivations, and though it may cost us some of the space that we would like to devote to mathematical material, we will 
insist, wherever our limited breadth allows, on discussing the problems of science (as opposed now to mathematics) side by side with those computational techniques developed to treat them. In recent years, the advent of large-scale computing machines has caused numerical analysis to become of such primary importance in science and technology that we would feel justified in writing the same book under the title, A Course in Applied Mathematics. We believe that boundary value problems as mathematical models for scientific and technological phenomena will be with us in some form for all time. Only very rarely can we expect to find solutions of these models in a closed (finitely generated) form. Thus, besides formulation of the model, existence, and uniqueness of the solution of the model, we must make approximation of solutions for boundary value problems using finitely generated functions the only ones we can compute - a basic concern in applied mathematics. This book is strongly oriented to that purpose."

His second book, "Theory of Partial Differential Equations", 1972, has the same approach. It is written in four parts and is intended to be "of value to researchers in computing, physics, and engineering laboratories and will also be excellent for graduate-level courses in mathematics, electrical engineering, aeronautical engineering, physics, physiology, and information sciences."

Nevertheless, Lieberstein does not, and never would, compromise his mathematics. The activity sometimes described as Engineering Mathematics is quite foreign to him and it is clear that from what-ever discipline they come, the students most likely to profit from his work are those with an outlook similar to his own students as described above.

"If the response to the present cry for relevance in mathematics is handled responsibly, an upsurge of interest in applied mathematics can be expected to occur."

This sentence is the first in Lieberstein's third book, "Mathematical Physiology"; it summarises his uncompromising approach to applied mathematics. He was quick, perhaps too quick, [25] at rebuking those whom he thought were not completely responsible in their approach to applied mathematics. This characteristic may have made him some enemies, but his great ability and insistence on mathematical probity earned him the respect of very many applied mathematicians, some of great distinction in their field.

His third book is primarily a monograph covering his research in mathematical physiology. It is written mainly for students in a graduate school of applied mathematics and accordingly, assumes no background knowledge of physiology. In his own words:

"since our primary audience is assumed to be students with no background whatsoever in physiology, we have never failed to provide general discussions of physiological principles before undertaking to treat them mathematically. In fact, the 
basis and philosophical background of our models are always discussed in great detail. In spite of all claims to the contrary, without this we feel that our analysis would be quite empty and pointless."

It is amazing that Mel, who was so productive in mathematical research and scholarship, should also have found the time and energy to devote to other interests. Nevertheless, there are those who will cherish his memory not as a mathematician, but as a willing helper and leader in community projects. In the Uniced States of America he had worked for the welfare and advancement of the American Indians and Negroes. Within a month of his arrival in Australia, he began to make enquiries concerning the Australian Aborigines, their culture, living conditions, social problems, etc. He read, avidly and with a great deal of understanding, everything he could find about Aborigines; within a very short time he had become something of an authority on their history, culture, social problems, modern Aboriginal advancement movements and their aims.

Mel became associated with the Hunter Region Aboriginal Co-operative Limited and was elected a foundation Director in April 1972. He was chosen by Aboriginal leaders to be a speaker at a conference of Aborigines in March 1973, when he spoke of the proposed Durungaling College for young Aboriginal women to be established in Newcastle, and also about his own Tel Aviv and Navaho Indian projects which had been adopted by the Aboriginal Co-operative. These latter projects were very dear to his heart, and he endeavoured to promote them with his usual enthusiasm and vigour.

The Tel Aviv project was proposed by Mel after his visit to Israel in 1972. He had been most impressed by the training centre at Tel Aviv called the AfroAsian Institute, where leaders from undeveloped countries were being trained in co-operative and community self-help programmes. He prevailed upon the Israeli authorities to accept Australian Aboriginal leaders for training, and asked the Federal Government to adopt this project and sponsor six Aboriginal leaders to go to Tel Aviv.

The Navaho Indian project aimed at bringing to Australia leaders of the Navaho Tribal Council to confer with Aboriginal leaders about community self-help projects in which the Navaho Indians have had some considerable success. The Navaho Indian Tribal Council has approved the plan and are now ready to send representatives to Australia.

One of Mel's hopes was to see the Durungaling Aboriginal Girls' Training College established in Newcastle, and he had a 'particular interest in seeing that an adequate library, with books dealing with Aboriginal culture and history, and with co-operative and community self-help programmes, were included as essentials in the library list. He was collecting books for this purpose, and his widow has promised these books and any other of Mel's books for the Durungaling College Library. The Board of Directors of the Co-operative has 
decided to dedicate the Durungaling Aboriginal Girls' Training College Library to Mel's memory and it will be known as the 'Mel Lieberstein Library'.

Both Mel and Mary-Anne were extremely interested in and fond of animals. In Kansas they had a farm with a large selection of animals, and they have written a book, as yet unpublished, on their life with these animals. In addition to providing entertainment, this book is intended to be a contribution to the behavioural sciences; the scientific aspects of his non-mathematical pursuits were seldom overlooked by Mel. This interest in flora and fauna continued at Newcastle where Mel became a leader in activities associated with conservation and the environment.

Professor Lieberstein will be greatly missed by his colleagues at the University of Newcastle and by mathematicians in Australia and overseas. Many of the projects he instigated did not come to fruition during his lifetime; for example, the newly-formed Division of Applied Mathematics of the Australian Mathematical Society originated largely through his initiatives. His death is also a grievous loss to that large number of people with whom he was closely associated in his non-mathematical activities.

\section{PUBLICATIONS BY H. M. LIEBERSTEIN}

BOOKS

[1] 'A Course in Numerical Analysis', Harper, New York (1968).

[2] 'Theory of Partial Differential Equations', Mathematics in Science and Engineering, Academic Press, New York and London (1972).

[3] 'Mathematical Physiology - Blood Flow and Electrically Active Cells', American Elsevier, New York (1973).

\section{ARTICLES}

[4] 'On a mixed problem for the Euler-Poisson-Darboux equation', J. Anal. Mathématiqe, 6 (1958), 357-379; addendum, 7 (1959), 188.

[5] 'On the numerical calculation of detached bow shock waves in hypersonic flow', (with P. R. Garabedian), J. Aeronautical Sci., 25 (1958), 109-118.

[6] 'On the generalized radiation problem of A. Weinstein', Pacific J. Math., 7 (1957), 1623-1640.

[7] 'Numerical solution of the boundary layer equations without similarity assumptions', (with R. Kramer), J. Aero-space Sci., 26 (1959), 508-514.

[8] 'A continuous method in numerical analysis applied to a new class of boundary value problems', Rendiconti di Mathematica (3-4), 19 (1960), 347-378.

[9] 'Further numerical data on Blunt Bodies', note in J. Aeronautical Sci. (1960).

[10] 'Determination of the tension versus stretch relation for a point in the aorta from measurement in vivo of pressure at three equally-spaced points', Acta Biotheoretica, XVII, Pars II (1965), 49-94.

[11] 'On the Hodgkin-Huxley partial differential equation', Math. Biosci., 1 (1967), 45-69.

[12] 'Numerical studies of the steady-state equations for a Hodgkin-Huxley model: Parts I, II, IIl', Math. Biosci., 1 (1967), 181-211. 
[13] 'Ephaptic initiation, a possible mechanism for electrical transmission in beds of membranous cells', Math. Biosci., 1 (1967), 213-225.

[14] 'Asymptotic uniqueness for elastic tube flows satisfying a Windkessel condition', (with Alan R. Elcrat), Math. Biosci., 1 (1967), 397-411.

[15] 'Some clarification in the mathematical theory of electrophoresis', Math. Biosci., 3 (1968), 399-412.

[16] 'The significance of viscous flow properties in the theory of operation of a nephron', Math. Biosci., 4 (1969), 49-100.

[17] 'Cell communication, a discourse and speculation on a possible role for mathematics in the developing theories of cancerous growth and immune reactions', Math. Biosci., 5 (1969), 403-418.

[18] 'A source of large inductance and concentrated moving magnetic fields on axons', (with M. A. Mahrous), Math. Biosci., 7 (1970), 41-60.

[19] 'A formulation concerning the electrical effects of axon variations from cylindrical shape, spindle cells and buibous synapses', (with M. A. Mahrous), Math. Biosci., 7 (1970), 259-272.

[20] 'Self-inhibition as a facet of sensory physiology clarifying a critical point in an emerging general theory of the electrical activity of cells', Math. Biosci., 11 (1971), 365-375.

[21] 'A possible four-mode operation of neurons and chains of fibroblasts: transmission mechanism for an early warning alert system', Math. Biosci., 12 (1971), 7-22.

[22] 'The basilar membrane as a uniformly loaded plate clamped on two spiral boundaries in a plane or on two helical-spiral boundaries: discussion of the model', Math. Biosci., 12 (1971), 281-291.

[23] "The basilar membrane as a uniformly loaded plate clamped on two spiral boundaries in a plane or on two helical-spiral boundaries: relevance of the species record', Math. Biosci., 13 (1972), 139-148.

[24] 'The steady-state demand output-waste economy', Proceedings of the Conference on Pollution: Engineering and Scientific Solutions, Tel Aviv, Plenum Press, June 12-17 (1972), 487503.

[25] 'Communities for native peoples, urban environment planning, and the utilisation of highly developed skil's', The International Technical Co operation Centre Special Congress Issue, (1973), 249-252.

[26] Letter to the Editor. Notices of the American Mathematical Society, 20, No. 2 (1973), 81.

[27] 'Mathematical treatment of some problems in physiology', Computers and Mathematics with Applications, inaugural issue, (1974).

Department of Mathematics

University of Newcastle

New South Wales 2308

Australia 